\title{
Comparison of precision and conventional irrigation management of cotton and impact of soil texture
}

\author{
E. Vories ${ }^{1}$ (D) S. O'Shaughnessy ${ }^{2} \cdot$ K. Sudduth ${ }^{3} \cdot$ S. Evett $^{2} \cdot$ M. Andrade . $^{4}$ \\ S. Drummond ${ }^{3}$
}

Published online: 3 August 2020

(c) The Author(s) 2020

\begin{abstract}
Soil textural variability diminishes the effectiveness of conventional irrigation management. Variable rate irrigation (VRI) can address soil variability; however, users need guidance to prepare prescriptions for optimal water application. A study was conducted at Portageville, MO, USA, in 2016 and 2017 with the objective to compare yield and irrigation water use efficiency among three water-management treatments for cotton: rainfed, irrigated based on the USDA-ARS Irrigation Scheduling Supervisory Control And Data Acquisition (ISSCADA) system, and irrigated based on a water balance method. Sand content in the top $533 \mathrm{~mm}$ soil layer was estimated from apparent electrical conductivity $\left(\mathrm{EC}_{\mathrm{a}}\right)$. Yield values measured near an $\mathrm{EC}_{\mathrm{a}}$ observation were averaged to create a data set containing sand content and associated yield. Although the trend was for the rainfed treatment to have the lowest yield in both years, the yield differences among all treatments were not significant when sand content was not considered. A strong effect of sand content on cotton yield was observed in both seasons, although the slopes differed among the water management treatments in 2016. The ISSCADA system tended to have a higher irrigation water use efficiency in both seasons, but the difference was not significant in 2016 when total irrigation applications were low. The study is continuing at Portageville and other locations and the ISSCADA system is constantly being improved to better meet the needs of agricultural producers.
\end{abstract}

Keywords Irrigation $\cdot$ Irrigation scheduling $\cdot$ Cotton $\cdot$ Soil apparent electrical conductivity $\cdot$ Variable rate irrigation

\section{E. Vories}

Earl.Vories@usda.gov

1 USDA-ARS CSWQRU, Portageville, MO, USA

2 USDA-ARS CPRL, Bushland, TX, USA

3 USDA-ARS CSWQRU, Columbia, MO, USA

4 University of Nevada, Reno, NV, USA 


\section{Introduction}

Irrigated agriculture in the USA is a major consumer of freshwater, accounting for approximately $80 \%$ of the nation's consumptive water use (Schaible and Aillery 2015). While irrigation is essential for crop production in arid and semi-arid regions, in recent years, irrigation has increased rapidly in more humid areas. Vories and Evett (2014) reported that while irrigated land in the US increased by 3.5 Mha (19\%) from 1988 to 2008, the increase in the US Mid-South over the same period was $1.2 \mathrm{Mha}(71 \%)$. The increase is related to the fact that with supplemental irrigation, crop yields attain on average $80 \%$ of potential yield in humid and sub-humid areas while rainfed crops attain on average $50 \%$ of potential yield (Lobell et al. 2009). Uncertainty in the amount and timing of precipitation is one of the most serious risks to crop production in those areas and timely irrigation has been shown to increase yields of cotton (Sui et al. 2017; Vories et al. 2007). Producers have become increasingly reliant on irrigation to ensure adequate yields and reduce production risks.

Irrigation scheduling systems include weather-based, soil moisture-based and plantbased methods. Weather-based methods schedule irrigation based on the estimated amount of water lost by plant evapotranspiration (ET) and the amount of effective rainfall and irrigation water entering the plant root zone. One weather-based system is the Arkansas Irrigation Scheduler (AIS), which has been in use for almost forty years in Arkansas and surrounding USA states to aid farmers in managing irrigation. The AIS uses a water-balance approach to schedule irrigation based on the soil water deficit (SWD). Rooting depth is not used explicitly in the program, but is implicit in the choice of a maximum allowable SWD. Cahoon et al. (1990) provided information about the program and Vories et al. (2009) reported on changes after the original publication.

Soil textural variability within many irrigated fields diminishes the effectiveness of conventional irrigation management with respect to irrigation uniformity, scheduling and water use efficiency. Irrigation scheduling methods that assume uniform soil conditions may produce less than satisfactory results on highly variable soils, contributing to lack of interest or commitment to irrigation scheduling even though, in general, scheduling improves overall crop production.

While soil sampling and testing a dense grid of locations within a field would be expensive and time consuming, mobile measurements of apparent soil electrical conductivity $\left(\mathrm{EC}_{\mathrm{a}}\right)$ have become widely used to map soil variability because $\mathrm{EC}_{\mathrm{a}}$ responds to a number of important soil properties, and mobile measurements are relatively quick and inexpensive. In non-saline soils, most of the variation in $\mathrm{EC}_{\mathrm{a}}$ is a function of soil texture, moisture content, bulk density and cation exchange capacity (CEC) (Corwin and Lesch 2005). Samples collected from the field and analyzed for texture can be used to relate texture and $\mathrm{EC}_{\mathrm{a}}$ in a field. Kitchen et al. (1996) used direct calibration of $\mathrm{EC}_{\mathrm{a}}$ to estimate depth of floodinduced sand deposition. Others have used $\mathrm{EC}_{\mathrm{a}}$ to estimate the topsoil depth above a subsoil claypan horizon (Doolittle et al. 1994) or to estimate soil texture over a complete profile or for specific layers (Sudduth et al. 2005). In some regions, fields contain very sandy areas that are too small to appear on most soil surveys (Freeland et al. 2008). Such areas can be important to irrigation management due to the low plant-available water associated with sand. Although the sandy areas will appear as relatively low $\mathrm{EC}_{\mathrm{a}}$, many soils used for cotton production have high sand content and the especially sandy areas might be difficult to differentiate from the surrounding soil.

Benefits of variable-rate application of agrochemicals, seeds and nutrients can be partially masked by applying inappropriate amounts of water. However, center pivot irrigation 
systems can be equipped with variable rate irrigation (VRI) capability for site-specific water application, and commercial VRI systems have been tested and shown to perform dependably (Han et al. 2009; O'Shaughnessy et al. 2013; Sui and Fisher 2015). While the development of VRI technology provides the opportunity to address some problems, several management questions remain unanswered (Stone et al. 2010; Rackers 2011).

The USDA-ARS team in Bushland, TX, USA, patented an Irrigation Scheduling Supervisory Control And Data Acquisition (ISSCADA) system (Evett et al. 2014) that can develop prescriptions and control VRI systems. With integrated sensor network subsystems, the ISSCADA system detects variable crop water needs and provides spatially variable recommendations for watering rates. These sensor network systems were a wireless network of infrared thermometers (IRTs) (SAP-IP IRTs, Dynamax, Inc., Houston, TX, USA) and weather data (air temperature, relative humidity, solar irradiance and wind speed) downloaded from a nearby weather station. The ISSCADA system requires two stationary IRTs located in well-watered areas in the field. These measurements are used as a reference temperature curve to scale the one-time-of-day measurements from IRTs $\left(T_{\mathrm{rmt}}\right)$ $\left({ }^{\circ} \mathrm{C}\right)$ located on the center pivot pipeline (Peters and Evett 2004). An integrated crop water stress index (iCWSI), calculated from the canopy temperature and weather data, was presented by O'Shaughnessy et al. (2012) to reduce some of the limitations of the traditional CWSI measurements. The iCWSI (Eq. 1) is based on the theoretical CWSI developed by Jackson et al. (1981) and is the sum of the CWSI calculated every 5 min. during daylight hours from 0900 to $1900 \mathrm{~h}$ :

$$
i C W S I=\sum_{i=0900}^{1900} \frac{\left(T_{r m t}-T_{a}\right)-\left(T_{c}-T_{a}\right)_{l l}}{\left(T_{c}-T_{a}\right)_{u l}-\left(T_{c}-T_{a}\right)_{l l}}
$$

where $T_{\mathrm{a}}$ is air temperature, $\left(T_{\mathrm{c}}-T_{\mathrm{a}}\right)_{11}$ is the lower limit of the index representing a wellwatered crop, and $\left(T_{\mathrm{c}}-T_{\mathrm{a}}\right)_{\mathrm{ul}}$ is the upper limit representing a non-transpiring leaf, with all units in ${ }^{\circ} \mathrm{C}$.

With the ISSCADA system, an irrigation event is triggered when an iCWSI threshold is exceeded, and a fixed amount of water is applied. Conversely, no irrigation is applied if the iCWSI threshold is not exceeded. This approach to triggering irrigation worked well in field tests in the USA Southern High Plains. Grain yields and water use efficiency (WUE) for crops irrigated at the highest treatment amounts resulted in similar or better yields and WUE than irrigations accomplished using a neutron probe (NP) (O'Shaughnessy and Evett 2010; O'Shaughnessy et al. 2012). It is uncertain how ISSCADA systems that rely solely on plant feedback will perform under extended periods of cloud cover and in climates with high humidity because the CWSI is less responsive to irrigation needs under those conditions (Bockhold et al. 2011). Furthermore, although the IRT sensors in the ISSCADA system view the crop at oblique angles and thus can report accurate canopy temperature data even under less than full cover, there is a lower limit of canopy cover below which temperature data may be influenced by soil background (e.g., soil is usually warmer than canopy). This may result in abnormally high iCWSI values and false irrigation triggers during partial canopy cover. The current version of the ISSCADA system includes soil water sensors to provide more direct measurements of crop irrigation requirements in space and time, and for different climates. The iCWSI and soil water content are both accounted for in the resulting irrigation recommendations.

The goal of this ongoing research is to test the ISSCADA system in a range of climates and determine ways to improve it. Previous work noted significant water management effects (Vories et al. 2019b) and soil effects (Vories et al. 2019c). This effort expanded on 
those studies with new data and more thorough analyses. The specific objectives of this study were to compare the yield of rainfed cotton and irrigated cotton based on the ISSCADA system and on the AIS, to compare the irrigation water use efficiency (IWUE) of the cotton between the two irrigation scheduling methods, and to investigate the impact of soil texture and variability on the irrigation response.

\section{Materials and methods}

A field study was conducted at the University of Missouri Fisher Delta Research Center Marsh Farm at Portageville $\left(36.41^{\circ} \mathrm{N}, 89.70^{\circ} \mathrm{W}\right)$ during the 2016 and 2017 growing seasons to investigate irrigated cotton production. The rectangular field is approximately 5 ha, $320 \mathrm{~m}$ by $156 \mathrm{~m}$, with the primary slope $\left(2 \mathrm{~mm} \mathrm{~m}^{-1}\right)$ in the south to north $(320 \mathrm{~m})$ direction and a cross slope $\left(1 \mathrm{~mm} \mathrm{~m}^{-1}\right)$ in the west to east $(156 \mathrm{~m})$ direction. The test field had been in corn production during 2013-2015.

The field is located roughly $14 \mathrm{~km}$ west of the Mississippi River and lies within the New Madrid seismic zone. The combination of alluvial, aeolian and seismic activity over the years has resulted in highly variable soils in the region. While farming activities, including precision land grading, have made the effects less obvious, they still exist. Soil mapping units within the field include Tiptonville silt loam (fine-silty, mixed, superactive, thermic Oxyaquic Argiudolls), which made up the majority of the field, and Reelfoot loam and sandy loam (fine-silty, mixed, superactive, thermic Aquic Argiudolls) (USDA-SCS 1971) (Fig. 1). The field also contains areas of high sand content that are too small to show up in the soil survey map.

To provide higher resolution soil information, mobile $\mathrm{EC}_{\mathrm{a}}$ data were collected on 13 June 2019. The DUALEM-1HS system (Dualem, Milton, ON, Canada) used has dualgeometry receivers at separations of 1 - and $1 / 2-\mathrm{m}$ from the transmitter to provide simultaneous 0.3-, 0.5-, 0.8- and 1.6-m depths of exploration (DOE; the depth at which 70\% of the cumulative response is obtained) (Dualem 2014). Data were collected on a 1-s interval at a $2.1 \mathrm{~m} \mathrm{~s}^{-1}$ overland speed and a 3.9-m transect spacing. Location of each data point was determined with a global navigation satellite system (GNSS), using an Ag Leader GPS 7500 receiver (Ag Leader Technology, Ames, IA, USA) with TerraStar-C Pro differential correction, with pass-to-pass accuracy of $30-60 \mathrm{~mm}$ (Ag Leader Technology 2019). An earlier $\mathrm{EC}_{\mathrm{a}}$ survey of the field was conducted in 2016 on a 9-m transect spacing with a lessprecise GNSS; however, with the high degree of textural variability observed, the narrower transect spacing and more precise location data were used in the follow-up survey.

Soil texture data (sand, silt and clay fractions) from laboratory analysis were obtained from 15 calibration locations (P1-P15, see Fig. 1) within the study field. The sampling locations were selected for their proximity to soil moisture sensors placed in the field. Soil cores, $51 \mathrm{~mm}$ in diameter and generally $838 \mathrm{~mm}$ in length, were divided into sections, with the uppermost section comprising the layer from the surface to $76 \mathrm{~mm}$ and each of the lower sections in $152 \mathrm{~mm}$ increments. The textural data from the 15 sampling sites in Fig. 1 were used to calibrate the $\mathrm{EC}_{\mathrm{a}}$ data. To construct a data set containing both $\mathrm{EC}_{\mathrm{a}}$ and texture, all $\mathrm{EC}_{\mathrm{a}}$ data points within $3 \mathrm{~m}$ of a sampling site were averaged. To calculate the combined texture from multiple depths, the weighted average of the individual cores was used. Linear regression was used to relate the data from each of the separate DOEs to the observed texture for the nearest depth (e.g., sand content from surface to $533 \mathrm{~mm}$ vs. $\mathrm{EC}_{\mathrm{a}}$ for $0.5 \mathrm{~m} \mathrm{DOE}$ ). 


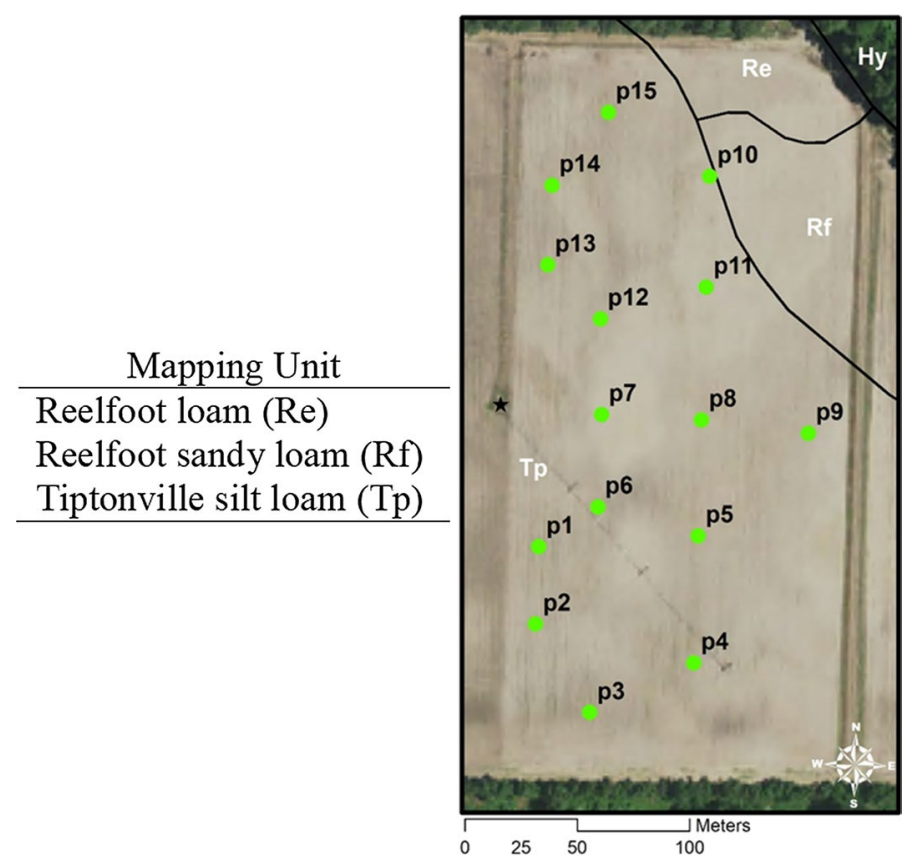

Fig. 1 Aerial image of study field with overlaid soil mapping units and locations of textural samples. The star represents the center pivot base

The field was bedded in the north-south direction with a row spacing of $0.97 \mathrm{~m}$ and the cotton variety PHY 333WRF was seeded at 13 seed $\mathrm{m}^{-1}$ on 23 May 2016 and 15 May 2017. Fertility was managed according to university recommendations (Stevens 2019) and standard pest management recommendations for producing irrigated cotton in Missouri were followed (Bradley et al. 2015). Fertilizer, growth regulator, insecticide and defoliant were applied as blanket treatments to the whole field.

The study field and adjoining field were irrigated using a $160 \mathrm{~m}$ Valley 6000 center pivot irrigation system (Valmont Irrigation, Valley, NE, USA) with a Valley Zone Control VRI system. The center pivot system was equipped with Nelson Universal Flo $70 \mathrm{kPa}$ pressure regulators and S3000 Spinner sprayheads (Nelson Irrigation Corporation, Walla Walla, WA, USA). The system included seven independently controlled zones of different lengths to achieve approximately equal area, except for the outermost zone, which consisted of the two sprinklers on the 5-m overhang beyond the outer drive tower. Three irrigation management treatments included variable rate irrigation based on the ISSCADA system (ISS), uniform irrigation based on the Arkansas Irrigation Scheduler (AIS), and no irrigation or rainfed (RF). The experimental plots each consisted of two adjacent VRI sprinkler zones (Fig. 2). The seventh zone was managed the same as the adjacent treatment, but the yield data were not included in the analyses because of the lack of coverage from adjacent sprinklers.

For the ISSCADA system, 12 Dynamax SapIP-IRT sensors (Dynamax, Inc., Houston, TX, USA) were mounted to the pivot lateral and two were placed at stationary locations within the field. The IRTs were included in a wireless network with a remote computer where the data were automatically collected, stored and analyzed. The system used the observed canopy temperatures, together with locally observed weather data, to calculate 
(a) 2016 plot layout

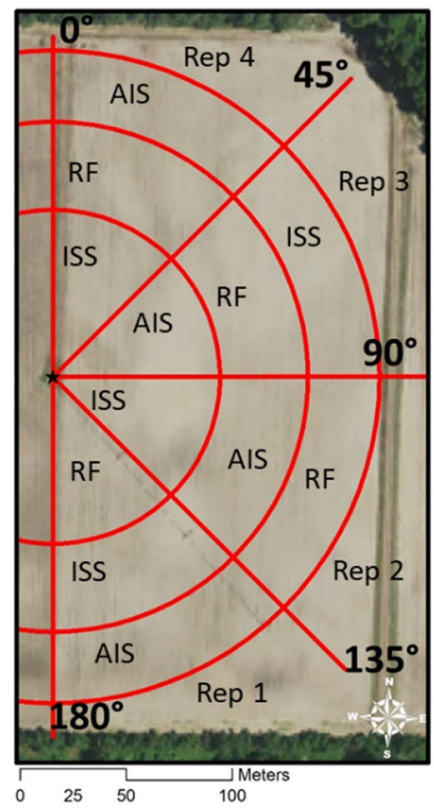

(b) 2017 plot layout

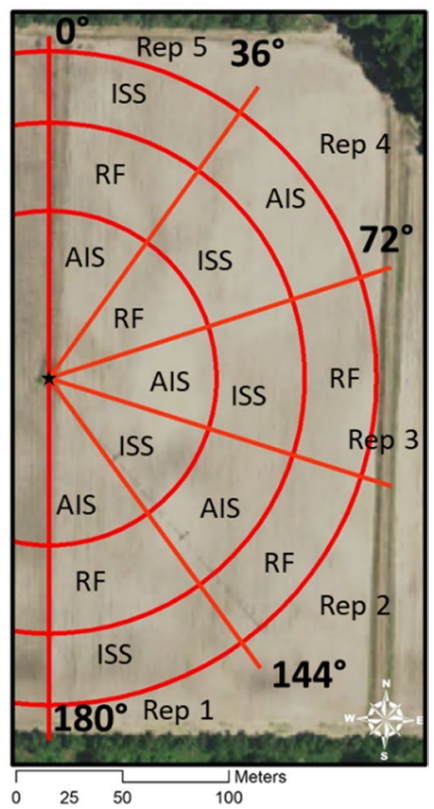

Fig. 2 Plot layouts for a 2016 and b 2017. Three irrigation management treatments included variable rate irrigation based on the ISSCADA system (ISS), uniform irrigation based on the Arkansas Irrigation Scheduler (AIS) and no irrigation or rainfed (RF). Plot boundaries along the center pivot lateral were at $78 \mathrm{~m}$, $120 \mathrm{~m}$ and $154 \mathrm{~m}$ from the pivot point. The star represents the center pivot base

iCWSI values for the irrigation management zones. Weather data were collected on a 5-min interval approximately $600 \mathrm{~m}$ from the most distant part of the study site and hourly and daily summaries were placed on the University of Missouri Agricultural Electronic Bulletin Board (AgEBB; https://agebb.missouri.edu/weather/realtime/portageville.asp). The irrigation application depth for the ISSCADA treatments were based on three tiers of the iCWSI:

If iCWSI $<200$ then irrigation was withheld;

If $200 \leq \mathrm{iCWSI}<250$ then the minimum depth of $6 \mathrm{~mm}$ was applied;

If $250 \leq \mathrm{iCWSI}<300$ then the medium depth of $13 \mathrm{~mm}$ was applied; and

If $\mathrm{iCWSI} \geq 300$ then the maximum depth of $22 \mathrm{~mm}$ was applied.

These values were derived from iCWSI values for cotton grown in previous studies using plant feedback for irrigation scheduling (O'Shaughnessy and Evett 2010; O'Shaughnessy et al. 2015). The maximum amount of irrigation was field-specific and based on the maximum application depth that could be applied without causing runoff. Although possible with the ISSCADA systems, soil water content was not considered in creating the irrigation prescriptions in this study.

After a few days without rain, the center pivot system was operated without water application to allow the ISSCADA system IRTs to scan the dry canopy. The daily 5-min weather data were downloaded at approximately midnight and used by the system with 
the canopy temperature data to calculate the iCSWI values and to prepare a VRI prescription for the following day. The ISSCADA system managed each replication independently of the others. The AIS (version 2.3.4) was updated daily from before planting through mid-August, the end of the cotton irrigation season in Missouri, using the daily summaries from the same weather station used by the ISSCADA system. A $19 \mathrm{~mm}$ application was applied to the AIS plots whenever the estimated SWD exceeded $38 \mathrm{~mm}$. In 2016, there were four replications of treatments, each comprising an arc of $45^{\circ}$, and there were five replications in 2017 , each comprising an $\operatorname{arc}$ of $36^{\circ}$ (Fig. 2a, b).

The crop was harvested on 10 November 2016 and 6, 7 October 2017 with a Case IH 2155 cotton spindle picker (Case IH, Racine, WI, USA) equipped with an Ag Leader Insight yield monitor system with sensors for every row. The system included an Ag Leader GPS 1500 receiver with Wide Area Augmentation System (WAAS) differential correction, which is expected to provide 150-200 mm pass-to-pass accuracy (Ag Leader Technology 2011). The whole field was harvested at a $1.6 \mathrm{~m} \mathrm{~s}^{-1}$ overland speed without regard to the individual plots (Fig. 2). The yield monitor was calibrated by placing the cotton from each load in a boll buggy equipped with scales and a new weight calibration specific to the test was created each year as directed (Ag Leader Technology 2002). Additional details concerning yield monitor calibration were included in Vories et al. (2019a). The boll buggy used in 2016 was built by Short Line Manufacturing (Shaw, Miss., USA). The unit was repaired and professionally calibrated in 2012. The boll buggy used in 2017 was built by Harrell Ag Products (Leesburg, GA, USA), with a weighing system added by Master Scales (Greenwood, MS, USA) in 2014. With both boll buggies, known weights were placed in the unit each year before harvest to ensure the weighing systems were working properly. Furthermore, the same boll buggy was used for all loads in the same year to avoid the errors observed by Rains et al. (2002) due to multiple weighing systems.

Spatially referenced yield data were obtained with the program SMS Basic 19.00 (Ag Leader Technology). Yield data were processed with the Yield Editor program (v. 2.07; Sudduth and Drummond 2007; Sudduth et al. 2012) using the Automated Yield Cleaning Expert (AYCE) function and recommended settings to remove erroneous data points. Any extraneous data points that appeared to be outside of the field but were not removed by the AYCE were manually removed from the data set.

To construct a data set containing both yield and soil texture, the aggregating procedure described by Griffin et al. (2007) and Vories et al. (2015) was followed. The spatially referenced textural data developed from the $\mathrm{EC}_{\mathrm{a}}$ survey was used and all yield data points within $1.8 \mathrm{~m}$ of an $\mathrm{EC}_{\mathrm{a}}$ and associated estimated sand content data point were averaged. Although the $\mathrm{EC}_{\mathrm{a}}$ survey utilized $3.9 \mathrm{~m}$ transects, the same width as a harvest pass and following approximately the same path as the harvester, the Ag Leader GPS 7500 receiver with TerraStar C-Pro differential correction used with the $\mathrm{EC}_{\mathrm{a}}$ survey provided more accurate location information than the Ag Leader GPS 1500 receiver with WAAS differential correction on the cotton harvester. The $1.8 \mathrm{~m}$ radius around an $\mathrm{EC}_{\mathrm{a}}$ data point was selected to be slightly less than the harvest pass width; therefore, multiple yield values that were averaged would be from adjacent points in the same pass rather than from separate harvest passes.

To account for overspray from adjacent nozzles, a 7-m buffer was placed on each side of each plot and the yield obtained in those areas was not used in the subsequent analyses. For the outermost zone, the overhang sprinklers (zone 7) served as the outer buffer. To estimate the irrigation water use efficiency (IWUE; i.e., the yield increase per unit of irrigation applied), the marginal yield was calculated as the average yield for the rainfed treatment 
subtracted from the yield for each irrigated plot. That marginal yield value was divided by the total irrigation application for the plot to calculate IWUE.

The large, spatially referenced data sets were managed with ArcGIS for Desktop 10.4.1 (ESRI, Redlands, CA, USA) and spatial analysis of variance (SANOVA) was conducted using GeoDa 1.8.16 (Center for Spatial Data Science, Univ. of Chicago, Chicago, IL, USA) using the spatial error model as recommended for yield monitor data (Griffin et al. 2007). SAS for Windows 9.4 (SAS Institute Inc., Cary, NC, USA) was used for the linear regression of the $\mathrm{EC}_{\mathrm{a}}$ data. Tests of significance were conducted at the alpha $=5 \%$ level.

\section{Results and discussion}

\section{Soil}

Multiple comparisons were tested relating \% sand and \% clay to $\mathrm{EC}_{\mathrm{a}}$ with a DOE nearest the depth of the texture measurement. The best fit $\left(\mathrm{R}^{2}=0.658\right)$ was between $\%$ sand in the top $533 \mathrm{~mm}$ and $\mathrm{EC}_{\mathrm{a}}$ for $0.5-\mathrm{m} \mathrm{DOE}$. The resulting data set (Fig. 3) contained 6324 data points with an average of $62 \%$ sand. Although most of the field and all but one of the calibration points were within the Tiptonville silt loam mapping unit (P10 was on the boundary between $\mathrm{Tp}$ and $\mathrm{Rf}$ ), the soil contained much more sand than the mapping unit would suggest. Two of the samples (P11, P15) were damaged and couldn't be tested for the complete $533 \mathrm{~mm}$. Of the remaining 13 samples, one of the samples was classified sand (P6),

(a) 2016 plots

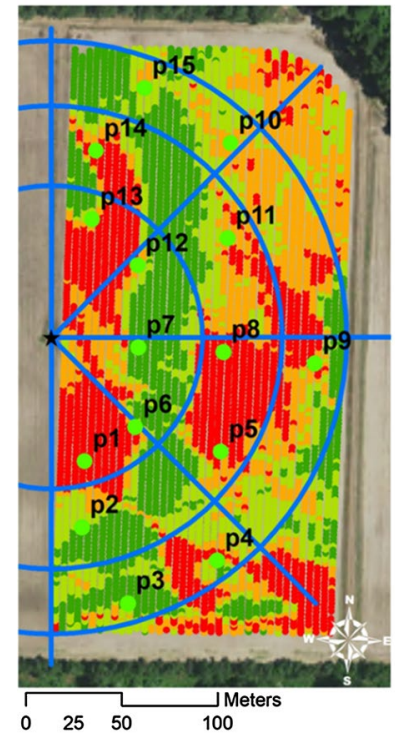

(b) 2017 plots

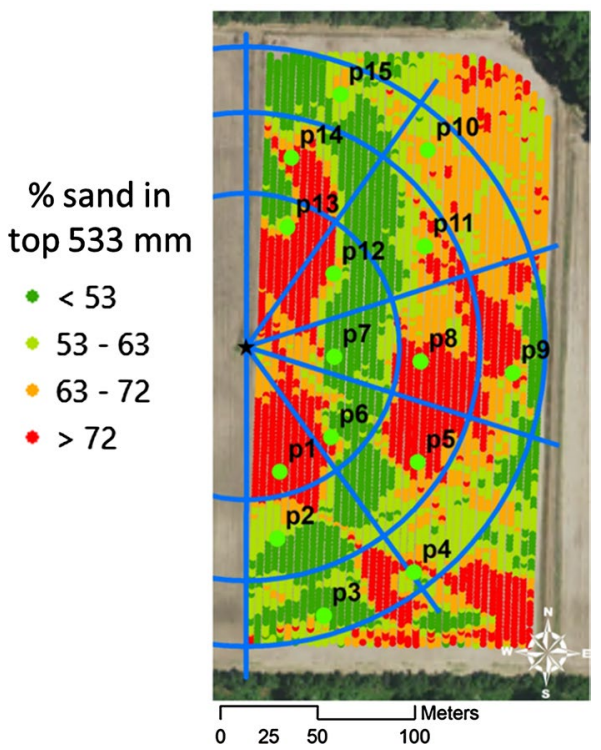

Fig. 3 Predicted sand content in the top $533 \mathrm{~mm}$ for a 2016 and b 2017 along with locations of textural samples. The blue radial lines and arcs represent the boundaries of the study plots and the star represents the center pivot base 
four were classified loamy sand (P1, P5, P8, and P9), four sandy loam (P10, P12, P13, and P14), and four loam (P2, P3, P4, and P7) (USDA-NRCS undated).

While a better fit is often possible in these non-saline soils, the layering of the soil textures in this field was not consistent. For example, site P3 consisted of loamy sand (0-76 mm), silt loam (76-229 mm), loam $(229-381 \mathrm{~mm})$ and clay loam $(381-838 \mathrm{~mm})$. Conversely, each layer at site P6 was sand $(0-685 \mathrm{~mm})$. While site P14 contained sand $(0-381 \mathrm{~mm})$ over loam $(381-533 \mathrm{~mm})$ over silt loam $(533-838 \mathrm{~mm})$, site P7 contained sandy loam (0-76 mm) over loam (76-685 mm) over silt loam $(685-838 \mathrm{~mm})$. Because the $\mathrm{EC}_{\mathrm{a}}$ response with depth is non-linear (Dualem 2014), the $\mathrm{EC}_{\mathrm{a}}$ associated with sand at one depth in the profile is not the same as for sand at a different depth. Precisely describing the soil in the field in all three dimensions would require a more in-depth study and probably additional calibration samples.

Once the estimated sand content was determined, the average sand contents associated with each treatment were compared to test for possible bias (Table 1). In 2016, there were no significant differences among the sand contents; however, in 2017, the AIS plots had an average of $12 \%$ more sand than the ISS plots. The RF plots, which would be most affected by high sand content, were not significantly different from either of the irrigated treatments (ISS, AIS).

\section{Weather and irrigation}

The 2016 and 2017 growing seasons were similar and typical for the region. Although planting was 8 days earlier in 2017, 7\% fewer Growing Degree Days (15.6 ${ }^{\circ} \mathrm{C}$ base) were measured during the irrigation period (planting through 17 August, when irrigation scheduling was terminated), while short grass reference evapotranspiration was $11 \%$ greater in 2017. While the total rainfall was similar both years, the timing differed greatly (Fig. 4). In 2017, there was only $2 \mathrm{~mm}$ of rain recorded from 9 July through 5 August, when crop water use is typically high. The result was that more irrigations were applied in 2017 (Table 2).

For AIS, each replication was irrigated the same amount on the same day; however, the ISSCADA-managed plots (ISS) were irrigated independently from each other. For example, in 2016, each ISS plot received a $22 \mathrm{~mm}$ irrigation on $13 \mathrm{July}$, but only one of the four received a second irrigation ( $6 \mathrm{~mm}$, the lowest recommended application, on 22 July). The additional irrigation was made in rep 1 (see Fig. 2), which had a less sandy soil than the ISS plot in rep 4 (see Fig. 3). While the sandier soils would be expected to need more frequent irrigation due to their lower water holding capacity, the smaller plants observed in the sandier plot were using less water than the plants in other parts of the field (Fig. 5). Even in cases where the total seasonal application was the same for two replications, the

Table 1 Average estimated sand content associated with irrigation treatments based on spatial analysis of variance using the spatial error model

\begin{tabular}{lll}
\hline Irrigation treatment & \multicolumn{2}{l}{ Average sand content (\%) } \\
\cline { 2 - 3 } & 2016 & 2017 \\
\hline ISSCADA (ISS) & $61 \mathrm{a}$ & $56 \mathrm{~b}$ \\
Arkansas Irrigation Scheduler (AIS) & $59 \mathrm{a}$ & $68 \mathrm{a}$ \\
Rainfed (RF) & $63 \mathrm{a}$ & $60 \mathrm{ab}$ \\
\hline
\end{tabular}

Values in a column within the same year and followed by the same letter are not significantly different at the alpha $=5 \%$ level 


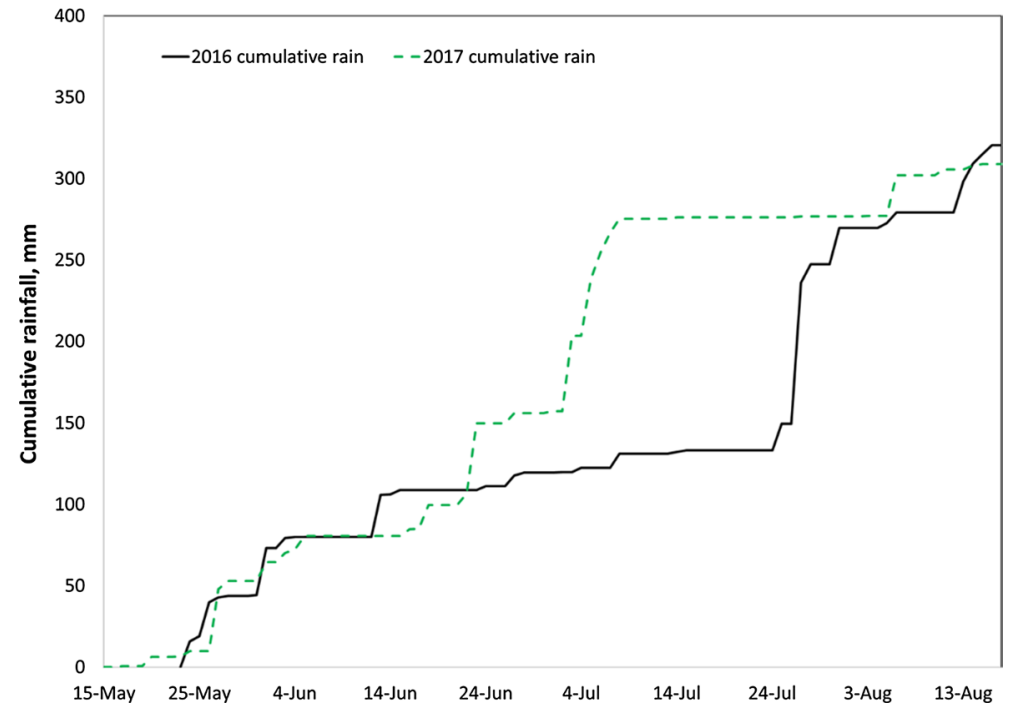

Fig. 4 Cumulative rainfall from planting through 17 August in 2016 and 2017

Table 2 Water applications to field from planting to 17 August, when irrigation scheduling was terminated

\begin{tabular}{llcr}
\hline Water application & ISSCADA (ISS) & $\begin{array}{l}\text { Arkansas irrigation } \\
\text { scheduler (AIS) }\end{array}$ & Rainfed (RF) \\
\hline 2016 & & & 0 \\
Number of irrigations & $1.25^{\mathrm{a}}$ & 2 & 0 \\
Total irrigation application (mm) & $24^{\mathrm{a}}$ & 38 & 321 \\
Total water applied (mm) & 345 & 359 & 0 \\
2017 & & 6 & 0 \\
Number of irrigations & $3.8^{\mathrm{a}}$ & 112 & 309 \\
Total irrigation application (mm) & $65^{\mathrm{a}}$ & 421 & \\
Total water applied (mm) & 374 & & \\
\hline
\end{tabular}

${ }^{\text {a }}$ Value is average of all replications

timing of the applications was sometimes different. In 2017, two of the five ISS plots received 5 irrigation applications for a total of $76 \mathrm{~mm}$; however, the final irrigation was 3 days earlier in rep 3, which had a higher sand content, than in rep 2 (Fig. 3).

\section{Yield}

The yield monitor calibration in 2016 was based on 9 of the 10 harvested loads. The first load routinely has larger errors, likely due to shifting of the residual cotton in the picker during transport and is normally not included in the calibration. The resulting calibration had a maximum error of $3.9 \%$ and an average of $2.3 \%$. The Insight system does not save GNSS diagnostic data; however, the location of the yield output appeared consistent (i.e., closely matched the row pattern) (Fig. 5a). In 2017, the calibration was again based on 


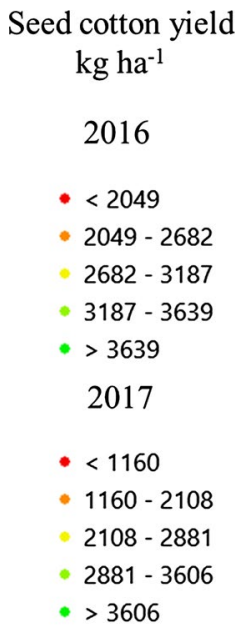

(a) 2016

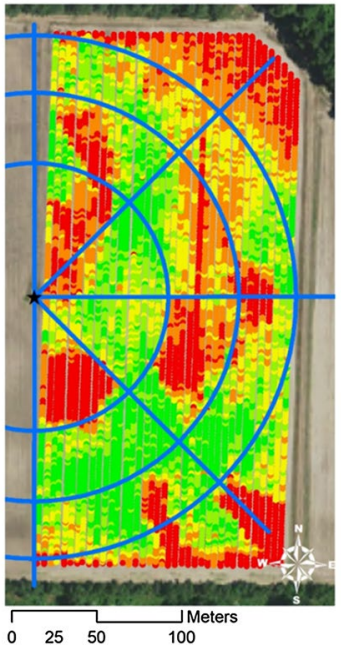

(b) 2017

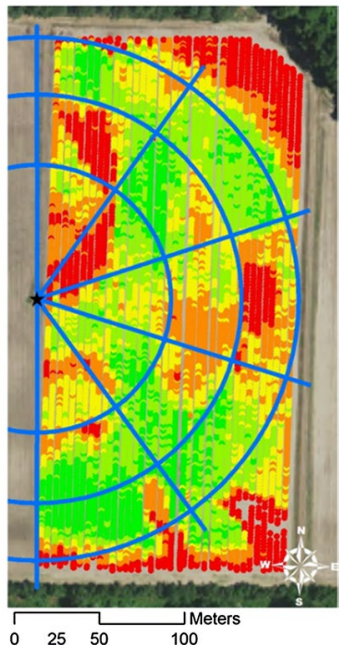

Fig. 5 Seed cotton yield quintiles $\left(\mathrm{kg} \mathrm{ha}^{-1}\right)$ for $\mathbf{a} 2016$ and b 2017. The blue radial lines and arcs represent the plot boundaries defined in Fig. 2 and the star represents the center pivot base

9 of the 10 harvest loads, resulting in a maximum error of $3.6 \%$ and an average of $2.7 \%$ (Fig. 5b).

The variability observed in the soil (Fig. 3) was reflected in the yield maps from the study field for both growing seasons (Fig. 5a, b). Some differences between the two seasons can be seen, likely due to the different randomization of irrigation treatments between the two years (Fig. 2). The highest quintile for both years was approximately the same, with $>3640$ and $>3610 \mathrm{~kg}$ seed cotton $\mathrm{ha}^{-1}$ in 2016 and 2017, respectively. However, the lowest quintile contained lower yield in 2017 , with $<2049$ and $<1160 \mathrm{~kg}$ seed cotton $\mathrm{ha}^{-1}$ in 2016 and 2017, respectively.

The yield quintiles were more similar after the lower-yielding areas outside the irrigation system were removed. The southeast corner of the field, beyond the center pivot system, contains a sandy area that seriously restricts plant growth and therefore always has low yield. The soil in the northeast corner of the field is less sandy (Fig. 3); however, surface drainage from the field can cause waterlogging in the corner after large rainfalls. While it does not affect the study area under the center pivot system, it is a common practice to use the dry corners of a center pivot field as the rainfed check in irrigation studies (e.g., Sui and Vories 2018; Vories et al. 2015); these data demonstrate that such areas are not always representative of the rest of the field.

In 2016, the resulting seed cotton yield data set contained 3219 points with an average of $2965 \mathrm{~kg} \mathrm{ha}^{-1}$. No significant differences were observed among the treatment mean yields (Table 3), although the significance level for comparing ISS and RF was near the traditional alpha $=5 \%$ cutoff $(\mathrm{p}=0.081)$. The lack of significant differences was not unexpected considering the soil variability and that no plot received more than two irrigation applications. When the water application (Table 2) was considered, the removal of the RF plots resulted in the data set being reduced to 2179 points with an average yield of $3063 \mathrm{~kg} \mathrm{ha}^{-1}$. The marginal yield (i.e., the seed cotton yield minus the RF treatment mean of $2790 \mathrm{~kg} \mathrm{ha}^{-1}$ ) averaged $273 \mathrm{~kg} \mathrm{ha}^{-1}$, and the IWUE averaged $0.9 \mathrm{~kg} \mathrm{~m}^{-3}$. The value for 
Table 3 Seed cotton yield and irrigation water use efficiency (IWUE) based on spatial analysis of variance using the spatial error model

\begin{tabular}{lll}
\hline Irrigation treatment & Seed cotton yield $\left(\mathrm{kg} \mathrm{ha}^{-1}\right)$ & IWUE $\left(\mathrm{kg} \mathrm{m}^{-3}\right)$ \\
\hline 2016 & & \\
ISSCADA (ISS) & $3162 \mathrm{a}^{\mathrm{a}}$ & $1.5 \mathrm{a}$ \\
Arkansas Irrigation Scheduler (AIS) & $2924 \mathrm{a}$ & $0.4 \mathrm{a}$ \\
Rainfed (RF) & $2790 \mathrm{a}$ & - \\
2017 & & \\
ISSCADA (ISS) & $2686 \mathrm{a}$ & $1.1 \mathrm{a}$ \\
Arkansas Irrigation Scheduler (AIS) & $2865 \mathrm{a}$ & $0.5 \mathrm{~b}$ \\
Rainfed (RF) & $2243 \mathrm{a}$ & - \\
\hline
\end{tabular}

Values in a column within the same year and followed by the same letter are not significantly different at the alpha $=5 \%$ level

AIS $\left(0.4 \mathrm{~kg} \mathrm{~m}^{-3}\right)$ was not significantly different from $0(\mathrm{p}=0.350)$ (Table 3$)$. Without large differences in yield or the amount of irrigation water applied (Table 2), the IWUE for ISS was not significantly greater than that for AIS (Table 3), although the significance level was near the alpha $=5 \%$ cutoff $(\mathrm{p}=0.062)$.

In 2017, the resulting seed cotton yield data set contained 3237 points with an average of $2714 \mathrm{~kg} \mathrm{ha}^{-1}$. The range of treatment mean yields was greater than in 2016, with ranges of 372 and $622 \mathrm{~kg}$ seed cotton $\mathrm{ha}^{-1}$ in 2016 and 2017, respectively; however, there were no significant differences among the treatments (Table 3). The removal of the RF plots resulted in the IWUE data set being reduced to 2110 points with an average of $2891 \mathrm{~kg} \mathrm{ha}^{-1}$. The marginal yield averaged $648 \mathrm{~kg} \mathrm{ha}^{-1}$ and the IWUE averaged $0.9 \mathrm{~kg} \mathrm{~m}^{-3}$. With the larger total water application associated with AIS, the IWUE for ISS was significantly greater than that for AIS in 2017, even though the yields were not significantly different. While the value for AIS was similar in both years, ISS had a lower IWUE in 2017, when more irrigation was required.

The value to the producer of an increase in IWUE without an associated increase in yield (i.e., the increased IWUE resulted from water savings) often depends on the location of the farm. For example, in the Portageville, MO, area where this study was conducted, irrigation water is pumped from a shallow aquifer; therefore, pumping costs are relatively small with no direct cost for the water and no limits on the amount of pumping. In areas where pumping costs are higher, where producers must pay for the water they use, and/or users are limited in their pumping volume, the economically best practice would be different. It will require longer term study with a broader range of weather conditions to find out if ISS can reliably increase yield compared with AIS, but both irrigation scheduling systems tended to increase yields compared to rainfed production.

\section{Interaction of irrigation and soil effects}

In 2016, the combined seed cotton yield and soil texture data set contained 3097 points with an average yield of $2976 \mathrm{~kg} \mathrm{ha}^{-1}$ and average estimated sand content of $61 \%$. The selection of a $1.8 \mathrm{~m}$ radius for averaging yield values around each $\mathrm{EC}_{\mathrm{a}}$ point meant that two yield values were averaged in most cases. Near the edge of a plot boundary, sometimes only one yield value was included, while in instances where the harvester slowed, 
more than two yield values were averaged. Overall, the yield values associated with each estimated texture point were the averages of from 1 to 5 yield data points, for an average of 1.8 , and the new yield values were assigned to the location of the $\mathrm{EC}_{\mathrm{a}}$ data point.

When significant interactions are present in the data, the level of the covariate will affect whether differences among treatments are significant; therefore, these data were compared at the field-average estimated sand content of $62 \%$. The mean values from the combined dataset (Table 4) were similar to the values from the original data set (Table 3), with no difference exceeding $50 \mathrm{~kg} \mathrm{ha}^{-1}$. However, the significance levels changed and yield of ISS was significantly greater than both AIS and RF, which were not significantly different from each other. Similarly, the mean values and significance levels were not greatly affected by including estimated sand content in the model; however, the interactions with sand content differed among the irrigation treatments. The RF treatment had a significantly steeper slope (i.e., decrease in yield with an increase in sand content) than the two irrigated treatments, whose slopes were significantly different from each other (Table 4). The effect for RF was expected, since drought stress would be more severe on sandier soil; however, with relatively small total irrigation amounts, the difference between ISS and AIS was not expected. The interactions shown in Table 4 are more obvious when the relationship is extrapolated over the full range of possible sand contents (Fig. 6a). The minimum and maximum sand contents of the calibration samples are indicated by vertical lines. ISS yield was always greater than both AIS and RF; however, RF exceeded AIS for sand content $<49 \%$. That is consistent with the lack of a significant difference between AIS and RF.

In 2017, the combined seed cotton yield and soil texture data set contained 2916 points with an average of $2668 \mathrm{~kg} \mathrm{ha}^{-1}$ and average estimated sand content of $60 \%$. The yield values were the averages of from 1 to 7 yield data points, for an average of 2.0 yield points

Table 4 Seed cotton yield at mean sand content with and without sand covariate, based on combined yield and texture dataset and spatial analysis of variance using the spatial error model

\begin{tabular}{|c|c|c|}
\hline \multirow[t]{2}{*}{ Irrigation treatment } & \multicolumn{2}{|c|}{ Seed cotton yield $\left(\mathrm{kg} \mathrm{ha}^{-1}\right)$} \\
\hline & Yield only & With covariate \\
\hline \multicolumn{3}{|l|}{2016} \\
\hline ISSCADA (ISS) & $3204 a$ & $3190 \mathrm{a}$ \\
\hline Arkansas Irrigation Scheduler (AIS) & $2956 b$ & $2747 b$ \\
\hline Rainfed (RF) & $2765 b$ & $2787 b$ \\
\hline \multicolumn{3}{|l|}{ Sand content interactions } \\
\hline ISS $\times$ Sand & - & $-9.9 b$ \\
\hline AIS $\times$ Sand & - & $-3.9 \mathrm{a}$ \\
\hline $\mathrm{RF} \times$ Sand & - & $-16.4 c$ \\
\hline \multicolumn{3}{|l|}{2017} \\
\hline ISSCADA (ISS) & $2787 \mathrm{a}$ & $2734 \mathrm{a}$ \\
\hline Arkansas Irrigation Scheduler (AIS) & $2796 a$ & $2864 \mathrm{a}$ \\
\hline Rainfed (RF) & $2312 \mathrm{a}$ & $2299 b$ \\
\hline \multicolumn{3}{|l|}{ Sand content interactions } \\
\hline ISS $\times$ Sand & - & $-7.9 \mathrm{a}$ \\
\hline AIS $\times$ Sand & - & $-11.2 \mathrm{a}$ \\
\hline $\mathrm{RF} \times$ Sand & - & $-10.3 \mathrm{a}$ \\
\hline Sand & - & -9.1 \\
\hline
\end{tabular}

${ }^{\text {a }}$ Values in a column within the same year and followed by the same letter are not significantly different at the alpha $=5 \%$ level 

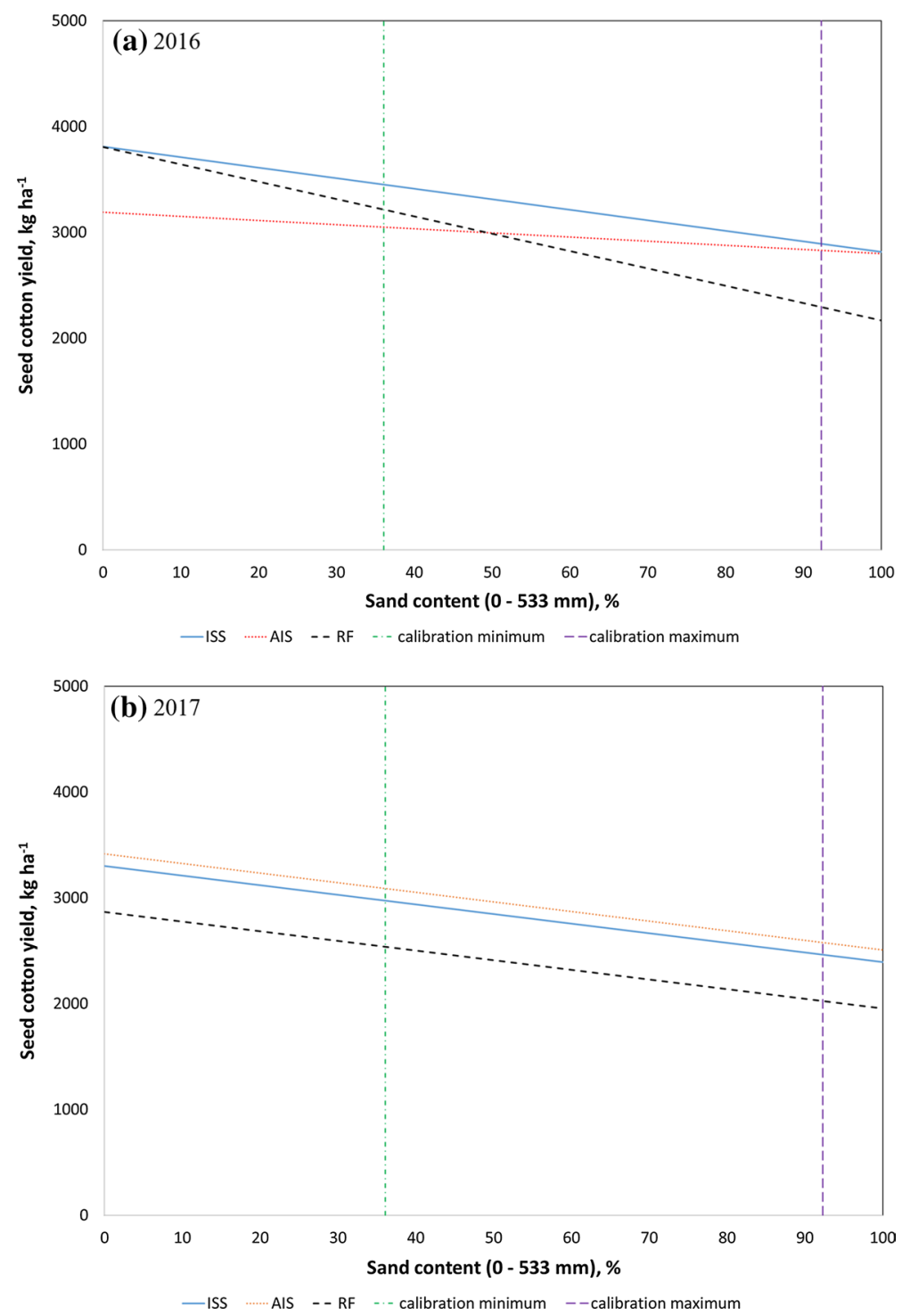

Fig. 6 Relationship between seed cotton yield and sand content for a 2016 and b 2017 with vertical lines noting the maximum and minimum values in the texture calibration samples, based on combined yield and texture dataset and spatial analysis of variance using the spatial error model

within $1.8 \mathrm{~m}$ of an estimated texture point. The data were tested at the field-average estimated sand content of $62 \%$ and, as observed with the original yield data set (Table 3), there were no significant differences among the treatments when sand content was not included in the model (Table 4, yield only). The differences between RF and both irrigation treatments were near the traditional alpha $=5 \%$ cutoff for significance, with $\mathrm{p}<0.084$ for both. When sand content was included, yield for RF was significantly less than for the irrigated treatments. The interactions with sand content were not significantly different among 
the treatments (Table 4); therefore, the single slope term $\left(-9.1 \mathrm{~kg} \mathrm{ha}^{-1} \% \mathrm{sand}^{-1}\right)$ best described the relationship. Unlike the previous year, the observed yield differences were independent of sand content (Fig. 6b), even though more irrigations were applied in 2017. Furthermore, the slope of the RF treatment was less than in 2016, even though water stress should have been more severe. The rainfall that occurred after 17 August may have allowed the plants to compensate for some of the earlier stress.

With the high degree of spatial autocorrelation associated with yield monitor data and the large amount of soil variability, spatial analysis methods are essential for this type of study. While the treatment mean values were similar with spatial and aspatial analyses, the results of statistical comparisons that did not account for spatial autocorrelation were quite different, with most of the comparisons suggesting significant differences. In addition, these data were based on harvesting the complete plot areas. Often the equipment necessary for such a study is not available and smaller subsets of the plots are harvested for analyses. With the high degree of soil variability (Fig. 3) and strong effect of sand content (Fig. 6), it would be easy to unintentionally bias the results due to the locations of the harvest plots. Both points demonstrate the importance of properly conducting studies under conditions of high soil variability and of using appropriate methods for analyzing the results.

Furthermore, the ability to rapidly collect spatially dense $\mathrm{EC}_{\mathrm{a}}$ data sets, which can often provide accurate estimates of soil texture in non-saline soils, is valuable to this and similar precision agriculture research and production practices on soils with appreciable spatial variability. The county soil survey indicated that the study field was relatively uniform, particularly the plot area under the center pivot system (Fig. 1); however, the 15 cores collected from the field indicated otherwise. The 13 June 2019 mobile $\mathrm{EC}_{\mathrm{a}}$ survey resulted in 6324 data points within the study field over the course of a few hours. Manually collecting and analyzing even $1 \%$ of those points would be extremely expensive in terms of both labor to collect the samples and laboratory costs to analyze them, and the resulting dataset would be insufficiently dense for analyses such as those presented in this paper.

Finally, additional study will be required to determine how best to include soil texture in the selection of management zones for VRI. In this study, the management zones were randomly assigned without regard to texture to conduct a replicated experiment. Each plot contained a range of soil textures that were combined for one irrigation recommendation. Selection of more texturally homogenous zones in future studies should enable the ISSCADA system to capitalize more effectively on the ability of VRI systems to make the necessary site-specific water applications. Furthermore, such zones should be more analogous to a producer's application of the system.

\section{Conclusions}

This 2-year study compared results from rainfed cotton to those from irrigated cotton and compared results from two irrigation scheduling methods in southeastern Missouri, USA. The Arkansas Irrigation Scheduler (AIS) method recommended a uniform irrigation application based on an estimated soil water deficit, while the USDA-ARS Irrigation Scheduling Supervisory Control And Data Acquisition (ISSCADA) system made site-specific recommendations based on an integrated crop water stress index (iCWSI). The principal findings of the study were: 
- While the total rainfall during the irrigation period of planting until mid-August was similar both years, the timing of the rainfall resulted in more irrigation applications and thus a greater total irrigation application in 2017.

- Although the trend was for the rainfed treatment to have the smallest yield in both years, the yield differences among all treatments were not significant in either year when not considering soil effects.

- Even though the yields between the two irrigation scheduling treatments were not significantly different in 2017, the lower total irrigation applications resulted in significantly greater IWUE for the ISSCADA-based treatment.

- A strong effect of sand content on cotton yield was observed in both seasons. Irrigation tended to reduce the negative yield effects associated with greater sand content as expected, although each treatment responded differently in 2016.

- While the ISSCADA system led to greater yields over the range of sand contents in 2016, the relationship between AIS-managed and rainfed cotton was dependent on the sand content. The relationship among the treatments was independent of sand content in 2017.

- Spatially dense soil texture data, accurately estimated from mobile $\mathrm{EC}_{\mathrm{a}}$ surveys, is increasingly important for advances in variable rate irrigation (VRI) and other precision agriculture practices.

Acknowledgements We acknowledge the support of Valmont Industries and Jake LaRue in this research, as well as the contributions of Andrea Jones. This material is in part based upon work that is supported by the National Institute of Food and Agriculture, U.S. Department of Agriculture, under Award Number 201667021-24420. Work reported in this paper was also accomplished as part of a Cooperative Research and Development agreement between USDA-ARS and Valmont Industries, Inc., Valley, NE (Agreement No.: 58-3K95-0-1455-M).

Disclaimer Mention of trade names or commercial products in this paper is solely for the purpose of providing specific information and does not imply recommendation or endorsement by the United States Department of Agriculture.

Open Access This article is licensed under a Creative Commons Attribution 4.0 International License, which permits use, sharing, adaptation, distribution and reproduction in any medium or format, as long as you give appropriate credit to the original author(s) and the source, provide a link to the Creative Commons licence, and indicate if changes were made. The images or other third party material in this article are included in the article's Creative Commons licence, unless indicated otherwise in a credit line to the material. If material is not included in the article's Creative Commons licence and your intended use is not permitted by statutory regulation or exceeds the permitted use, you will need to obtain permission directly from the copyright holder. To view a copy of this licence, visit http://creativecommons.org/licenses/by/4.0/.

\section{References}

Ag Leader Technology. (2002). Cotton harvest insert. Ames, IA, USA: Ag Leader Technology.

Ag Leader Technology. (2011). GPS differential sources explained. Retrieved July 21, 2020, from https:// www.agleader.com/blog/gps-differential-sources-explained/.

Ag Leader Technology. (2019). GPS 7500 and GPS 6500 correction signal comparison. Retrieved July 21, 2020, from https://portal.agleader.com/community/s/article/CorrectionSignalComparison?langu age $=$ en_US.

Bockhold, D. L., Thompson, A. L., Sudduth, K. A., \& Henggeler, J. C. (2011). Irrigation scheduling based on crop canopy temperature for humid environments. Transactions of the ASABE, 54(6), 2021-2028.

Bradley, K. W., Sweets, L. E., Bailey, W. C., Jones, M. M., \& Heiser, J. W. (2015). 2015 Missouri pest management guide: Corn, grain sorghum, soybean, winter wheat, rice, cotton. Univ. Mo. Ext. M171. 
Columbia, MO, USA: University of Missouri. Retrieved July 21, 2020, from https://weedscience.misso uri.edu/publications/m00171.pdf.

Cahoon, J., Ferguson, J., Edwards, D., \& Tacker, P. (1990). A microcomputer-based irrigation scheduler for the humid mid-South region. Applied Engineering in Agriculture, 6(3), 289-295.

Corwin, D. L., \& Lesch, S. M. (2005). Apparent soil electrical conductivity measurements in agriculture. Computers and Electronics in Agriculture, 46(1), 11-43.

Doolittle, J. A., Sudduth, K. A., Kitchen, N. R., \& Indorante, S. J. (1994). Estimating depths to claypans using electromagnetic induction methods. Journal of Soil and Water Conservation, 49(6), 572-575.

Dualem. (2014). DUALEM 1HS user's manual. Milton, ON, Canada: Dualem Inc.

Evett, S. R., O’Shaughnessy, S. A., \& Peters, R. T. (2014). Irrigation scheduling and supervisory control and data acquisition system for moving and static irrigation systems. USA patent no. 8,924,031, December $30,2014$.

Freeland, R. S., Ammons, J. T., \& Wirwa, C. L. (2008). Ground penetrating radar mapping of agricultural landforms within the New Madrid seismic zone of the Mississippi embayment. Applied Engineering in Agriculture, 24(1), 115-122.

Griffin, T. W., Brown, J. P., \& Lowenberg-DeBoer, J. (2007). Yield monitor data analysis protocol: A primer in the management and analysis of precision agriculture data. Retrieved July 21, 2020, from https:// www.agriculture.purdue.edu/SSMC/publications/YieldDataAnalysis2007.pdf.

Han, Y. J., Khalilian, A., Owino, T. W., Farahani, H. J., \& Moore, S. (2009). Development of Clemson variable-rate lateral irrigation system. Computers and Electronics in Agriculture, 68(1), 108-113.

Jackson, R. D., Idso, S. B., Reginato, R. J., \& Pinter, P. J., Jr. (1981). Canopy temperature as a crop water stress indicator. Water Resources Research, 17(4), 1133-1138. https://doi.org/10.1029/WR017i004p 01133.

Kitchen, N. R., Sudduth, K. A., \& Drummond, S. T. (1996). Mapping of sand deposition from 1993 Midwest floods with electromagnetic induction measurements. Journal of Soil and Water Conservation, 51(4), 336-340.

Lobell, D. B., Cassman, K. G., \& Field, C. B. (2009). Crop yield gaps: Their importance, magnitudes, and causes. Annual Review of Environment and Resources, 34, 179-204. https://doi.org/10.1146/annur evfienviron.041008.093740.

O’Shaughnessy, S. A., \& Evett, S. R. (2010). Canopy temperature based system effectively schedules and controls center pivot irrigation of cotton. Agricultural Water Management, 97(9), 1310-1316.

O’Shaughnessy, S. A., Evett, S. R., \& Colaizzi, P. D. (2015). Dynamic prescription maps for site-specific variable rate irrigation of cotton. Agricultural Water Management, 159, 123-138. https://doi. org/10.1016/j.agwat.2015.06.001.

O’Shaughnessy, S. A., Evett, S. R., Colaizzi, P. D., \& Howell, T. A. (2012). A crop water stress index and time threshold for automatic irrigation scheduling. Agricultural Water Management, 107, 122-132.

O’Shaughnessy, S. A., Urrego, Y. F., Evett, S. R., Colaizzi, P. D., \& Howell, T. A. (2013). Assessing application uniformity of a variable rate irrigation system in a windy location. Applied Engineering in Agriculture, 29(4), 497-510.

Peters, R. T., \& Evett, S. R. (2004). Modeling diurnal canopy temperature dynamics using one time-of-day measurements and a reference temperature curve. Agronomy Journal, 96, 1553-1561.

Rackers, A. D. (2011). Development and application of variable rate irrigation techniques on non-uniform soils using center-pivot irrigation systems. Unpublished MS thesis, University of Missouri, Columbia, MO, USA.

Rains, G. C., Perry, C. D., Vellidis, G., Thomas, D. L., Wells, N., Kvien, C. K., et al. (2002). Cotton yield monitor performance in changing varieties. ASAE paper no. 021160. St. Joseph, MI, USA: ASAE.

Schaible, G., \& Aillery, M. (2015). Irrigation \& water use. Retrieved July 21, 2020, from https://www.ers. usda.gov/topics/farm-practices-management/irrigation-water-use.aspx.

Stevens, G. (2019). Cotton fertility management. Columbia, MO, USA: University of Missouri.

Stone, K. C., Bauer, P., Busscher, W., Millen, J., Evans, D., \& Strickland, E. (2010). Variable-rate irrigation management for peanut in the eastern coastal plain. Paper no. IRR10-8977. St Joseph, MI, USA: ASABE.

Sudduth, K. A., \& Drummond, S. T. (2007). Yield editor: Software for removing errors from crop yield maps. Agronomy Journal, 99(6), 1471-1482.

Sudduth, K. A., Drummond, S. T., \& Myers, D. B. 2012. Yield editor 2.0: Software for automated removal of yield map errors. Paper no. 121338243. St Joseph, MI, USA: ASABE.

Sudduth, K. A., Kitchen, N. R., Wiebold, W. J., Batchelor, W. D., Bollero, G. A., Bullock, D. G., et al. (2005). Relating apparent electrical conductivity to soil properties across the north-central USA. Computers and Electronics in Agriculture, 46, 263-283. 
Sui, R., Byler, R. K., \& Delhom, C. D. (2017). Effect of nitrogen application rate on yield and quality in irrigated and rainfed cotton. Journal of Cotton Science, 21(2), 113-121.

Sui, R., \& Fisher, D. K. (2015). Field test of a center pivot irrigation system. Applied Engineering in Agriculture, 31(1), 83-88.

Sui, R., \& Vories, E. (2018). Comparison of sensor-based irrigation scheduling method and Arkansas irrigation scheduler. In Proceedings 2018 irrigation show \& education conference. Fairfax, VA, USA: Irrigation Association. Retrieved July 21, 2020, from https://www.irrigation.org/IA/FileUploads/IA/Resou rces/TechnicalPapers/2018/Comparison_of_Sensor_Based_Irr_SUI.pdf.

USDA-NRCS. Undated. Soil texture calculator. Washington, DC, USA: USDA. Retrieved July 21, 2020, from https://www.nrcs.usda.gov/wps/portal/nrcs/detail/soils/survey/?cid=nrcs142p2_054167.

USDA-SCS. (1971). Soil survey, Pemiscot County, Missouri. Washington, DC, USA: USDA.

Vories, E. D., \& Evett, S. R. (2014). Irrigation challenges in the sub-humid US Mid-South. International Journal of Water, 8(3), 259-274.

Vories, E. D., Hogan, R., Tacker, P., Glover, R., \& Lancaster, S. (2007). Estimating the impact of delaying irrigation for Midsouth cotton on clay soil. Transactions of the ASABE, 50(3), 929-937.

Vories, E. D., Jones, A. S., Meeks, C. D., \& Stevens, W. E. (2019a). Variety effects on cotton yield monitor calibration. Applied Engineering in Agriculture, 35(3), 345-354.

Vories, E., O’Shaughnessy, S., \& Andrade, M. (2019b). Comparison of precision and conventional irrigation management of cotton. In J. V. Stafford (Ed.), Precision Agriculture '19_Proceedings of the 12th European Conference on Precision Agriculture (pp. 695-702). Wageningen, Netherlands: Wageningen Academic Publishers.

Vories, E. D., Stevens, W. E., Sudduth, K. A., Drummond, S. T., \& Benson, N. R. (2015). Impact of soil variability on irrigated and rainfed cotton. Journal of Cotton Science, 19(1), 1-14.

Vories, E., Sudduth, K., \& Drummond, S. (2019c). Interaction of irrigation and soil effects on cotton yield. In K. A. Sudduth, N. R. Kitchen, and K. S. Veum (Eds.), 5th global workshop on proximal soil sensing, PSS 2019, program and proceedings (pp. 141-146). Retrieved July 21, 2020, from https://docs.wixst atic.com/ugd/8dcced_4763e8b0465944e0b965dba92fb999ae.pdf.

Vories, E., Tacker, P., \& Hall, S. (2009). The Arkansas irrigation scheduler. In S. Starrett (Ed.), World environmental and water resources congress 2009: Great Rivers (pp. 1-10). Reston, VA, USA: ASCE.

Publisher's Note Springer Nature remains neutral with regard to jurisdictional claims in published maps and institutional affiliations. 